\title{
Adiposity, adult weight change and breast cancer risk in postmenopausal Japanese women: the Miyagi Cohort Study
}

\author{
M Kawai', Y Minami*,2, S Kuriyama ${ }^{3}$, M Kakizaki $^{3}$, Y Kakugawa $^{4}$, Y Nishino $^{5}$, T Ishida' ${ }^{1}$ A Fukao ${ }^{6}$, I Tsuji $^{3}$ \\ and N Ohuchi'
}

'Department of Surgical Oncology, Tohoku University Graduate School of Medicine, I I Seiryo-machi, Aoba-ku, Sendai, Miyagi 980-8574, Japan; ${ }^{2}$ Division of Community Health, Tohoku University Graduate School of Medicine, 2-I Seiryo-machi, Aoba-ku, Sendai, Miyagi 980-8575, Japan; ${ }^{3}$ Division of Epidemiology, Department of Public Health and Forensic Medicine, Tohoku University Graduate School of Medicine, 2-I Seiryo-machi,

Aoba-ku, Sendai, Miyagi 980-8574, Japan; ${ }^{4}$ Division of Surgery, Miyagi Cancer Center, 47-I Nodayama, Medeshima-Shiode, Natori, Miyagi 981 - I 293 , Japan; ${ }^{5}$ Division of Epidemiology, Miyagi Cancer Center Research Institute, 47-I Nodayama, Medeshima-Shiode, Natori, Miyagi 98I-I 293, Japan;

${ }^{6}$ Department of Public Health, Yamagata University School of Medicine, 2-2-2 lida-nishi, Yamagata 990-9585, Japan

BACKGROUND: The role of adult weight change in breast cancer (BC) risk is unclear in Japanese women.

METHODS: A total of 10106 postmenopausal women aged 40-64 years (the Miyagi Cohort) were followed from 1990 to 2003, and $108 \mathrm{BC}$ cases were identified. Hazard ratios (HRs) were estimated according to body mass index (BMI) at the current age and at the of age 20 years, and weight change since age 20 years.

RESULTS: Higher current BMI was associated with an increased risk of BC ( $P$ for trend $=0.02)$, whereas higher BMI at the age 20 years was inversely associated with this risk $(P$ for trend $=0.002)$. There was a significant association between weight change since age 20 years and $\mathrm{BC}$ risk $(P$ for trend $=0.0086)$. Compared with stable weight, $\mathrm{HR}$ was 0.35 for weight loss of $5 \mathrm{~kg}$ or more $(P$ for weight loss trend $=0.04$ ) and 1.55 for weight gain of $12 \mathrm{~kg}$ or more ( $P$ for weight gain trend $=0.05)$.

CONCLUSION: Adiposity at younger and current age has differential effects on BC risk among postmenopausal women; weight gain in adulthood being associated with an increased, and weight loss with a decreased risk.

British Journal of Cancer (20 I0) 1 03, I443- |447. doi:I0.1038/sj.bjc.6605885 www.bjcancer.com

Published online 14 September 2010

(c) 2010 Cancer Research UK

Keywords: breast cancer; cohort study; body weight; body mass index; incidence

The incidence of breast cancer (BC) shows variations among countries and although Japan has a lower risk of BC than Western countries, its age-standardised incidence is the highest among female cancers, and it is increasing (Matsuda et al, 2008). The increase of $\mathrm{BC}$ incidence may be attributed to a change in the proportion of women in the population who have reproductive and anthropometric risk factors (Minami et al, 2004). Among such risk factors, the associations between adiposity and $\mathrm{BC}$ risk have been extensively investigated, mainly in the Western countries (Lahmann et al, 2004; Morimoto et al, 2002; Reeves et al, 2007). In relation to adiposity, weight gain has also been associated with an increased risk of postmenopausal BC in several prospective studies (Ahn et al, 2007; Barnes-Josiah et al, 1995; Eliassen et al, 2006; Feigelson et al, 2004; Lahmann et al, 2005). In Japan, however, few prospective studies have evaluated the association with adiposity (Iwasaki et al, 2007; Kuriyama et al, 2005). Also, data are sparse regarding the effect of body weight change (Hirose et al, 1999; Kyogoku et al, 1990).

We therefore conducted a population-based cohort study, in which we evaluated the association of adiposity in different periods, that is, at current age and at age 20 years, with BC risk and examined the change in risk resulting from body weight gain and

*Correspondence: Dr Y Minami; E-mail: adym@med.tohoku.ac.jp Received 7 June 2010; revised 2 August 20 I0; accepted 9 August 20 I0; published online 14 September 2010 loss since the age of 20 years among postmenopausal Japanese women.

\section{MATERIALS AND METHODS}

Our analysis used the Miyagi Cohort Study, whose design has been described in detail elsewhere (Fukao et al, 1995; Kawai et al, 2010). Briefly, 25279 men and 26642 women aged 40-64 years living in 14 municipalities, selected randomly from among the 62 municipalities in Miyagi Prefecture, Northeastern Japan, were entered into a cohort on 1 June 1990. A self-administered questionnaire on various health aspects was delivered to these subjects between June and August 1990. Usable questionnaires were returned by 22836 men $(90.3 \%)$ and 24769 women (93.0\%). After excluding men, women with a history of cancer $(n=705)$, who were premenopausal $(n=9131)$, with undefined menopausal status $(n=642)$ and for whom data on menopausal status were missing $(n=2927)$, 11364 postmenopausal women remained (Kawai et al, 2010). After further excluding women with missing data or extreme values for current height or current weight or weight at age 20 years ( $n=1258), 10106$ postmenopausal women contributed to this study. The study protocol was approved by the institutional review board of Tohoku University School of Medicine. We considered the return of self-administered questionnaires signed by the subjects to imply their consent to participate in the study. 
The questionnaire covered personal history including current height (centimeters) and weight (kilograms) and weight at age 20 years and details of general lifestyle including menstrual and reproductive histories. The self-reported current height and weight data were highly correlated with measured data (correlation coefficient: 0.82 for height and 0.97 for weight) in a subsample of postmenopausal women $(n=2921)$, although we were unable to validate the data for weight at age 20 years.

As a measure of adiposity, body mass index (BMI) was used. The BMI at the current age and at age 20 years, calculated as weight divided by the square of current height $\left(\mathrm{kg} \mathrm{m}^{-2}\right)$, respectively. To analyze $\mathrm{BC}$ risk for adiposity in the different periods, the study women were categorised using quartile points of BMI at age 20 years, respectively: $<20.5, \geqslant 20.5-<22.0, \geqslant 22.0-<23.8$ and $\geqslant 23.8$. Subjects with a current BMI of 23.8 and higher were further divided into two groups on the basis of median value in the range between 23.8 and the largest current BMI, as the BMI at the current age was skewed towards a higher value than at age 20 years. Finally, women were categorised as follows: current BMI $<20.5, \geqslant 20.5-<22.0, \geqslant 22.0-<23.8, \geqslant 23.8-<25.9$ and $\geqslant 25.9$; BMI at age $20<20.5, \geqslant 20.5-<22.0, \geqslant 22.0-<23.8$ and $\geqslant 23.8$. Weight change from age 20 years to the current age was calculated as the difference between current weight and weight at age 20 . Subjects were also categorised into seven groups as follows: weight loss of $\leqslant-5$ and $>-5$ to $\leqslant-2$, stable weight of $>-2$ to $<+2$, and weight gain of $\geqslant+2$ to $<+5, \geqslant+5$ to $<+8, \geqslant+8$ to $<+12$ and $\geqslant+12$. The categorisation of weight loss was based on the median value, and that of weight gain was determined using quintile values.

Women were followed from the start of the study (1 June 1990) until 31 December 2003. The end point of our analysis was BC defined as the topography codes C50.0-C50.9 according to the International Classification of Disease for Oncology, Second Edition, and confirmed by the Miyagi Prefecture Cancer Registry, one of the oldest and most accurate population-based in Japan (Curado et al, 2007). In this registry, the percentage registered by death certificates only for BC was 2.5\% during 1991-2003. A follow-up committee was also established, consisting of the Miyagi Cancer Society, the Divisions of Community Health of all 14 municipalities, the Department of Health and Welfare, Miyagi Prefectural Government, and the Division of Epidemiology, Tohoku University School of Medicine. The committee periodically reviewed the residential registration record of each municipality. During the study period, 491 women $(4.9 \%)$ were lost to follow-up because of emigration.

\section{Statistical analysis}

The person-years of follow-up were counted for each of the subjects from the start of the study (1 June 1990) until the date of diagnosis of $\mathrm{BC}$, the date of emigration from the study area, the date of death, or the end of follow-up (31 December 2003), whichever occurred first. The mean follow-up period was 12.8 years. The Cox proportional-hazard regression model was used to estimate BC hazard ratios (HRs) and 95\% confidence intervals (CIs) according to category of exposure variable, that is, BMI at the current age, BMI at age 20 years and weight change from age 20 years to the current age, and to adjust for confounding variables (Cox, 1972). Linear trends, which were tested using the Cox model by treating each exposure category as a continuous variable, were regarded as significant if $P$-values were $<0.05$. We considered the following variables as potential confounders: age, education level, cigarette smoking, alcohol drinking, and time spent walking, which are known or suspected risk factors for BC. Menstrual and reproductive factors, exogenous female hormone use, and history of BC in the mother or sisters, some of which had been established as risk factors in our previous study (Kawai et al, 2010), were also considered to be adjusted for each other. In the analysis of weight change, height and weight at age 20 years were further adjusted for (Eliassen et al, 2006). Missing values for confounders were treated as an additional variable category, and were included in the model. To evaluate any independent effect of BMI during the different periods, analysis adjusting for both BMIs each other was also conducted. All statistical analyses were performed using the SAS software package (version 9.1; SAS Institute, Cary, NC ,USA).

\section{RESULTS}

The characteristics of the study subjects are presented in Tables 1 and 2. The subjects with a higher current BMI were less likely to smoke, whereas the subjects with a higher BMI at age 20 years tended to be older and to have a shorter period of education (Table 1). A total of $64.8 \%$ of the subjects had gained more than $2 \mathrm{~kg}$ since age 20 years (Table 2). The subjects who lost weight were heavier at age 20 years.

During 129891 person-years of follow-up, 108 BC cases were documented. Table 3 shows the HRs and 95\% CIs according to current BMI and BMI at age 20 years. After adjustment for confounding variables, current BMI was marginally associated with an increased BC risk ( $P$ for trend in multivariate-adjusted model $1=0.07)$. The BMI at age 20 years was inversely associated risk ( $P$ for trend in multivariate-adjusted model $1=0.01$ ). Postmenopausal women with a BMI of $\geqslant 23.8$ at age 20 years showed half the risk (multivariate-adjusted $\mathrm{HR}=0.44,95 \% \mathrm{CI}$ : $0.24-0.81$ ) of women with a BMI of $<20.5$. Multivariate analysis adjusting for both BMIs each other demonstrated a stronger inverse association for BMI at age 20 years ( $P$ for trend in multivariate-adjusted model $2=0.002)$. The association of current BMI with risk was statistically significant $(P$ for trend $=0.02$ ).

Weight change since the age of age 20 years was significantly associated with the risk (multivariate-adjusted $P$ for trend= 0.0086) (Table 4). Compared with women whose weight had been stable (lost or gained $<2.0 \mathrm{~kg}$ ), those who lost $5 \mathrm{~kg}$ or more were at a lower risk (multivariate-adjusted HR 0.35, 95\% CI: $0.11-1.10$ ). Women with a weight gain of $12 \mathrm{~kg}$ or more appeared to have a higher risk (HR 1.55, 95\% CI: $0.70-3.45$ ). According to weight loss and gain, weight loss was associated with a decreased risk ( $P$ for weight loss trend $=0.04)$, and weight gain with an increased risk ( $P$ for weight gain trend $=0.05$ ). Although the data are not shown in the table, stratified analysis by the BMI at age 20 years revealed a clearer inverse association with weight loss among women who were heavier at age 20 years (BMI at age 20 years $\geqslant 23.8$; $P$ for weight loss trend $=0.01$ ).

\section{DISCUSSION}

In this population-based cohort study, we found associations between adulthood adiposity and weight change and BC risk among postmenopausal women. Risk differed for BMI between that at current age and that at age 20 years. Weight change from age 20 to current age was significantly associated with risk. These results provide some insight into the significance of adiposity and weight change in terms of $\mathrm{BC}$ risk in postmenopausal Japanese women.

This study found a positive association of current BMI with postmenopausal BC risk consistent with previous prospective studies (Iwasaki et al, 2007; Kuriyama et al, 2005; Lahmann et al, 2004; Morimoto et al, 2002; Reeves et al, 2007), and the fact that postmenopausal obese women have more oestrogens than lean women (Potischman et al, 1996), has a central role in BC aetiology. After menopause, oestrogen is synthesised mainly by aromatase in adipose tissue (Bulun et al, 2005). Another mechanism is that obese women may be in a state of hyperinsulinemia, insulin being a growth factor for BC cells. Insulin-like growth factor I may also affect risk among heavier women (Muti et al, 2002). On the other 
Table I Characteristics of study population according to body mass index (BMI)

\begin{tabular}{|c|c|c|c|c|c|}
\hline & $<20.5$ & $\leqslant 20.5<22.0$ & $\leqslant 22.0<23.8$ & $\leqslant 23.8<25.9$ & $\leqslant 25.9$ \\
\hline \multicolumn{6}{|l|}{ Current BMI } \\
\hline Number of subjects & 1209 & 1497 & 2335 & 2516 & 2549 \\
\hline Age (mean, years) & $57.2 \pm 4.5$ & $57.0 \pm 4.4$ & $57.1 \pm 4.3$ & $57.2 \pm 4.3$ & $57.5 \pm 4.2$ \\
\hline Occupation (no occupation/housewife, \%) & 15.4 & 15.5 & 17.3 & 16.6 & 17.1 \\
\hline Educational level (college/university or higher, \%) & 12.4 & 12.8 & 12.5 & 11.7 & 10.3 \\
\hline Alcohol drinking (drinkers, \%) & 19.5 & 19.0 & 18.6 & 19.1 & 18.8 \\
\hline Smoking (smokers, \%) & 10.3 & 7.6 & 5.9 & 5.7 & 5.8 \\
\hline Walking status ( < I h per day, \%) & 44.7 & 46.6 & 45.1 & 46.1 & 49.2 \\
\hline Family history of breast cancer in mother or sisters (\%) & 1.8 & 1.7 & 2.3 & 2.0 & 2.0 \\
\hline Age at menarche (mean, years) & $15.4 \pm 2.1$ & $15.3 \pm 1.9$ & $15.3 \pm 2.0$ & $15.2 \pm 2.0$ & $15.2 \pm 2.1$ \\
\hline Age at menarche ( 16 years $\leqslant, \%)$ & 37.2 & 35.9 & 36.2 & 34.7 & 32.4 \\
\hline Age at natural menopause (mean, years) & $49.1 \pm 3.8$ & $49.5 \pm 3.6$ & $49.4 \pm 3.4$ & $49.4 \pm 3.7$ & $49.7 \pm 3.7$ \\
\hline Parity (nulliparous, \%) & 3.7 & 2.7 & 1.8 & 2.3 & 2.2 \\
\hline Parity number among parous women (mean) & $2.6 \pm 1.0$ & $2.6 \pm 1.0$ & $2.7 \pm 1.0$ & $2.7 \pm 1.0$ & $2.8 \pm 1.1$ \\
\hline Exogenous female hormone use (users, \%) & 11.7 & 10.6 & 9.9 & 10.8 & 10.0 \\
\hline \multirow[t]{2}{*}{ Height (mean, cm) } & $152.4 \pm 6.7$ & $151.7 \pm 5.2$ & $151.5 \pm 5.0$ & $151.5 \pm 4.9$ & $150.7 \pm 5.3$ \\
\hline & $<\mathbf{2 0 . 5}$ & $\leqslant 20.5<22.0$ & $\leqslant 22.0<23.8$ & $\leqslant \mathbf{2 3 . 8}$ & \\
\hline \multicolumn{6}{|l|}{ BMl at age 20 years } \\
\hline Number of subjects & 2577 & 2460 & 2594 & 2475 & \\
\hline Age (mean, years) & $56.9 \pm 4.4$ & $57.1 \pm 4.3$ & $57.3 \pm 4.3$ & $57.6 \pm 4.2$ & \\
\hline Occupation (no occupation/housewife, \%) & 19.0 & 17.1 & 16.3 & 14.0 & \\
\hline Educational level (college/university or higher, \%) & 14.0 & 12.7 & 10.8 & 9.5 & \\
\hline Alcohol drinking (drinkers, \%) & 20.0 & 17.5 & 18.6 & 19.6 & \\
\hline Smoking (smokers, \%) & 7.3 & 6.0 & 6.1 & 6.8 & \\
\hline Walking status ( < I h per day, \%) & 48.7 & 45.6 & 47.0 & 44.7 & \\
\hline Family history of breast cancer in mother or sisters (\%) & 2.3 & 1.5 & 2.1 & 2.0 & \\
\hline Age at menarche (mean, years) & $15.4 \pm 2.0$ & $15.2 \pm 1.9$ & $15.3 \pm 2.0$ & $15.3 \pm 2.1$ & \\
\hline Age at menarche $(16$ years $\leqslant, \%)$ & 36.7 & 33.3 & 35.0 & 34.7 & \\
\hline Age at natural menopause (mean, years) & $49.3 \pm 3.7$ & $49.4 \pm 3.5$ & $49.5 \pm 3.7$ & $49.6 \pm 3.6$ & \\
\hline Parity (nulliparous, \%) & 3.7 & 2.0 & 2.0 & 1.8 & \\
\hline Parity number among parous women (mean) & $2.6 \pm 1.0$ & $2.7 \pm 1.0$ & $2.7 \pm 1.1$ & $2.8 \pm 1.1$ & \\
\hline Exogenous female hormone use (users, \%) & 11.6 & 9.9 & 10.2 & 10.1 & \\
\hline Height (mean, cm) & $152.9 \pm 5.8$ & $|5| .6 \pm 4.7$ & $|5| .0 \pm 5.0$ & $150.2 \pm 5.4$ & \\
\hline
\end{tabular}

Table 2 Characteristics of study population according to weight change from age 20 to the current age

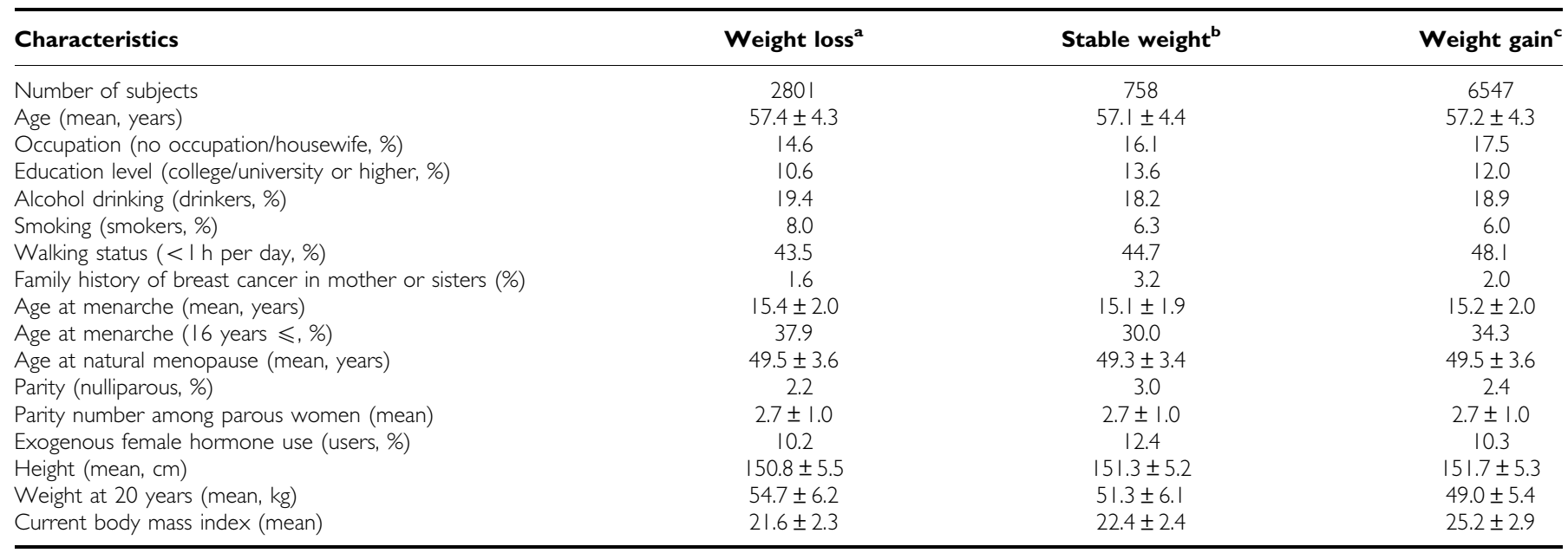

Weight change was evaluated for subjects with complete data for height. ${ }^{a}$ Weight loss $\geqslant 2 \mathrm{~kg}$. ${ }^{b}$ Weight gain or loss $<2 \mathrm{~kg}$. ${ }^{9}$ Weight gain $\geqslant 2 \mathrm{~kg}$.

hand, a higher BMI at age 20 years was significantly associated with a decreased postmenopausal risk. This inverse association, which has also been observed in the Western countries (Ahn et al, 2007; Morimoto et al, 2002; Sellers et al, 1992; van den Brandt et al, 1997), was independent of the effect of current BMI. The Nurses' Health Study recently reported the independent protective effect of body fatness at young age using a pictogram (Baer et al, 2010).
Although the mechanisms explaining this inverse association are poorly understood, lower serum oestradiol and progesterone levels and anovulation among young obese women may reduce BC risk after menopause (Potischman et al, 1996).

There was a significant association between weight change since age 20 and postmenopausal risk. Weight gain was associated with an increased risk, and weight loss with a decreased risk. 


\section{ACKNOWLEDGEMENTS}

This work was supported by a grant for the Scientific Research from the Ministry of Education, Culture, Sports, Science, and Technology, Japan (grant nos: H20-Kiban C-20590630, H21-Kiban C-21590681) and in part by the third Term Comprehensive Control Research for Cancer (grant no. H18-Senryaku-001,

\section{REFERENCES}

Ahn J, Schatzkin A, Lacey Jr JV, Albanes D, Ballard-Barbash R, Adams KF, Kipnis V, Mouw T, Hollenbeck AR, Leitzmann MF (2007) Adiposity, adult weight change, and postmenopausal breast cancer risk. Arch Intern Med 167: $2091-2102$

Baer HJ, Tworoger SS, Hankinson SE, Willett WC (2010) Body fatness at young ages and risk of breast cancer throughout life. Am J Epidemiol 171: $1183-1194$

Barnes-Josiah D, Potter JD, Sellers TA, Himes JH (1995) Early body size and subsequent weight gain as predictors of breast cancer incidence (Iowa, United States). Cancer Causes Control 6: 112-118

Bulun SE, Lin Z, Imir G, Amin S, Demura M, Yilmaz B, Martin R, Utsunomiya H, Thung S, Gurates B, Tamura M, Langoi D, Deb S (2005) Regulation of aromatase expression in estrogen-responsive breast and uterine disease: from bench to treatment. Pharmacol Rev 57: 359-383

Cox DR (1972) Regression models and life-tables (with discussion). J Roy Statist Soc 34: 187-220

Curado MP, Edwards B, Shin HR, Storm H, Ferlay J, Heanue M, Boyle P (2007) Cancer Incidence in Five Continents, Vol. IX IARC Scientific Publications No. 160: Lyon

Eliassen AH, Colditz GA, Rosner B, Willett WC, Hankinson SE (2006) Adult weight change and risk of postmenopausal breast cancer. JAMA 296: $193-201$

Feigelson HS, Jonas CR, Teras LR, Thun MJ, Calle EE (2004) Weight gain, body mass index, hormone replacement therapy, and postmenopausal breast cancer in a large prospective study. Cancer Epidemiol Biomarkers Prev 13: $220-224$

Fukao A, Tsubono Y, Komatsu S, Tsuji I, Minami Y, Hisamichi S, Hosokawa T, Kawamura M, Takano A, Sugawara N, Ikeda T, Nishikori M (1995) A cohort study on the relation of lifestyle, personality and biologic markers to cancer in miyagi, japan: study design, response rate and profiles of the cohort subjects. J Epidemiol 5: 153-157

Harvie M, Howell A, Vierkant RA, Kumar N, Cerhan JR, Kelemen LE, Folsom AR, Sellers TA (2005) Association of gain and loss of weight before and after menopause with risk of postmenopausal breast cancer in the Iowa women's health study. Cancer Epidemiol Biomarkers Prev 14: $656-661$

Hirose K, Tajima K, Hamajima N, Takezaki T, Inoue M, Kuroishi T, Miura S, Tokudome S (1999) Effect of body size on breast-cancer risk among Japanese women. Int J Cancer 80: 349-355

Iwasaki M, Otani T, Inoue M, Sasazuki S, Tsugane S (2007) Body size and risk for breast cancer in relation to estrogen and progesterone receptor status in Japan. Ann Epidemiol 17: 304-312

Kawai M, Minami Y, Kuriyama S, Kakizaki M, Kakugawa Y, Nishino Y, Ishida T, Fukao A, Tsuji I, Ohuchi N (2010) Reproductive factors, exogenous female hormone use and breast cancer risk in Japanese: the Miyagi Cohort Study. Cancer Causes Control 21: 135-145

Kuriyama S, Tsubono Y, Hozawa A, Shimazu T, Suzuki Y, Koizumi Y, Ohmori K, Nishino Y, Tsuji I (2005) Obesity and risk of cancer in Japan. Int $J$ Cancer 113: $148-157$
H21-Ippan-003) from the Ministry of Health, Labour and Welfare of Japan.

\section{Conflict of interest}

The authors declare no conflicts of interest.
Kyogoku S, Hirohata T, Takeshita S, Hirota Y, Shigematsu T (1990) Anthropometric indicators of breast cancer risk in Japanese women in Fukuoka. Jpn J Cancer Res 81: $731-737$

Lahmann PH, Hoffmann K, Allen N, van Gils CH, Khaw KT, Tehard B, Berrino F, Tjonneland A, Bigaard J, Olsen A, Overvad K, Clavel-Chapelon F, Nagel G, Boeing H, Trichopoulos D, Economou G, Bellos G, Palli D, Tumino R, Panico S, Sacerdote C, Krogh V, Peeters PH, Bueno-deMesquita HB, Lund E, Ardanaz E, Amiano P, Pera G, Quiros JR, Martinez C, Tormo MJ, Wirfalt E, Berglund G, Hallmans G, Key TJ, Reeves G, Bingham S, Norat T, Biessy C, Kaaks R, Riboli E (2004) Body size and breast cancer risk: findings from the European Prospective Investigation into Cancer And Nutrition (EPIC). Int J Cancer 111: $762-771$

Lahmann PH, Schulz M, Hoffmann K, Boeing H, Tjonneland A, Olsen A, Overvad K, Key TJ, Allen NE, Khaw KT, Bingham S, Berglund G, Wirfalt E, Berrino F, Krogh V, Trichopoulou A, Lagiou P, Trichopoulos D, Kaaks R, Riboli E (2005) Long-term weight change and breast cancer risk: the European Prospective Investigation into Cancer and Nutrition (EPIC). Br J Cancer 93: 582 - 589

Matsuda T, Marugame T, Kamo K, Katanoda K, Ajiki W, Sobue T (2008) Cancer incidence and incidence rates in Japan in 2002: based on data from 11 population-based cancer registries. Jpn J Clin Oncol 38: 641 - 648

Minami Y, Tsubono Y, Nishino Y, Ohuchi N, Shibuya D, Hisamichi S (2004) The increase of female breast cancer incidence in Japan: emergence of birth cohort effect. Int J Cancer 108: 901-906

Morimoto LM, White E, Chen Z, Chlebowski RT, Hays J, Kuller L, Lopez AM, Manson J, Margolis KL, Muti PC, Stefanick ML, McTiernan A (2002) Obesity, body size, and risk of postmenopausal breast cancer: the Women's Health Initiative (United States). Cancer Causes Control 13: $741-751$

Muti P, Quattrin T, Grant BJ, Krogh V, Micheli A, Schunemann HJ, Ram M, Freudenheim JL, Sieri S, Trevisan M, Berrino F (2002) Fasting glucose is a risk factor for breast cancer: a prospective study. Cancer Epidemiol Biomarkers Prev 11: $1361-1368$

Potischman N, Swanson CA, Siiteri P, Hoover RN (1996) Reversal of relation between body mass and endogenous estrogen concentrations with menopausal status. J Natl Cancer Inst 88: 756-758

Reeves GK, Pirie K, Beral V, Green J, Spencer E, Bull D (2007) Cancer incidence and mortality in relation to body mass index in the Million Women Study: cohort study. BMJ 335: 1134

Rothman KJ, Greenland S (1998) Modern epidemiology, 2nd edn Lippincott-Raven: Philadelphia

Sellers TA, Kushi LH, Potter JD, Kaye SA, Nelson CL, McGovern PG, Folsom AR (1992) Effect of family history, body-fat distribution, and reproductive factors on the risk of postmenopausal breast cancer. $N$ Engl J Med 326: 1323 - 1329

van den Brandt PA, Dirx MJ, Ronckers CM, van den Hoogen P, Goldbohm RA (1997) Height, weight weight change, and postmenopausal breast cancer risk: The Netherlands Cohort Study. Cancer Causes Control 8: $39-47$ 